\title{
Psychomotor therapy targeting anger and aggressive behaviour in individuals with mild or borderline intellectual disabilities: A systematic review
}

\author{
Tina Bellemans (ib) ${ }^{\mathrm{a}, \mathrm{b}}$, Robert Didden ${ }^{\mathrm{b}, \mathrm{c}}$, Jooske T. van Busschbach ${ }^{\mathrm{a}, \mathrm{d}}$, Pim T. A. P. Hoek ${ }^{\mathrm{a}}$, Mia W. J. Scheffers ${ }^{\mathrm{a}}$, \\ Russell B. Lang and William R. Lindsay ${ }^{\mathrm{f}}$
}

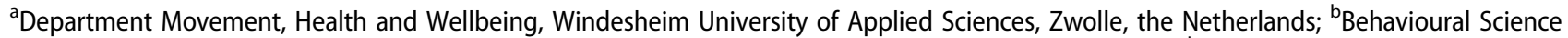

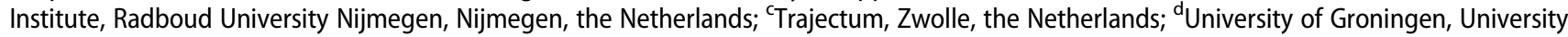
Medical Center of Psychiatry, Groningen, the Netherlands; ${ }^{~}$ Clinic for Autism Research Evaluation and Support, Texas State University, San Marcos, TX, USA; 'Danshell Healthcare, Scotland, UK
\end{abstract}

\begin{abstract}
Background: Poor anger regulation is considered a risk factor of aggression in individuals with mild or borderline intellectual disabilities. Psychomotor therapy (PMT) targets anger regulation through body- and movement-oriented interventions. This study aims to inform practitioners on efficacy and research-base of PMT in this population.

Method: This systematic review evaluated nine studies which met inclusion criteria in terms of participants, intervention procedures, outcomes and certainty of evidence.

Results: Seven studies revealed a substantial reduction of aggressive behaviour or anger. Certainty of evidence was rated inconclusive in most cases due to absence of experimental control.

Conclusions: We can conclude that body-oriented PMT, involving progressive relaxation and meditation procedure "Soles of the Feet", is a promising approach. However, the paucity of studies and methodological limitations preclude classifying it as an evidence-based practice. This suggests stronger methodological research and research aimed at PMT's mechanisms of action (e.g., improved interoceptive awareness) is warranted.
\end{abstract}

KEYWORDS

Psychomotor therapy; bodyoriented; mild or borderline intellectual disabilities; anger; aggressive behaviour
Estimates of the prevalence of aggression among individuals with intellectual disability, including those with mild or borderline intellectual disability (MBID), have reported that as many as $20 \%$ may engage in some form of aggression (Davies \& Oliver, 2013; Lundqvist, 2013). Verbal and physical aggression are the most frequently reported typologies and are the leading cause for treatment referral in this population (Crotty, Doody, \& Lyons, 2014). Both severe physical aggression that may result in bodily injury as well as milder forms of aggression (verbal threats) have the potential to adversely affect the individual with MBID, their family and support staff by leading to isolation, stigmatisation, resource drain and mental health sequela (Hensel, Lunsky, \& Dewa, 2014; Woods \& Ashley, 2007). Given the prevalence and range of adverse consequences associated with aggression, it is not surprising that a great deal of research has focused on the cause and treatment of aggression in people with MBID (e.g., Brosnan \& Healy, 2011; Larkin, Jahoda, \& MacMahon, 2013).

One potential factor suggested to contribute to the increased risk of aggressive behaviour in people with MBID involves deficient anger regulation or limited anger management skills. In the absence of the ability to sufficiently regulate one's own emotional response, relatively benign environmental stimuli may produce disproportional emotional arousal (i.e., undue anger) that may ultimately manifest in acts of aggression (Novaco, 1994; Taylor \& Novaco, 2005). Successful anger regulation is hypothesised to require: (a) awareness of the social situations that may evoke the emotional state of "anger"; (b) the ability to identify body signals indicating a building anger (Mehling et al., 2012); and (c) a repertoire of coping skills to effectively and adaptively control anger and calm one's self before acts of aggression occur (Gratz \& Roemer, 2004). This approach is similar to the Social Information Processing Model (see Larkin et al., 2013) focusing in particular on the arousal, physiological reactions or body signals related to anger in a given social situation.

Based on this model, treatment procedures for reducing aggressive behaviour in individuals with MBID have focused on improving anger regulation and teaching coping skills (see, e.g., Didden et al., 2016). Three specific types of coping skills have been considered, including: (a) physiological coping skills (e.g., relaxation 
or breathing exercises); (b) behavioural or sociallymediated coping skills (e.g., seeking help); and (c) cognitive coping skills (e.g., problem-solving). For people without intellectual disability, cognitive behavioural therapy (CBT) techniques have been demonstrated to be effective at improving these abilities. Systematic reviews have concluded that there is some evidence supporting the effectiveness of CBT in treating anger or aggressive behaviour in individuals with MBID but note that many studies have methodological shortcomings (Ali, Hall, Blickwedel, \& Hassiotis, 2015; Hamelin, Travis, \& Sturmey, 2013; Nicoll, Beail, \& Saxon, 2013; Vereenooghe \& Langdon, 2013). For individuals with intellectual or developmental disabilities, it has been suggested that the behavioural components of CBT (e.g., role play, prompting and reinforcing specific target behaviours) may contribute more to CBT's effectiveness than components focused on correcting faulty cognitive processes due to deficits in communication, abstract thinking and other skills associated with those diagnoses (Didden et al., 2016; Hamelin et al., 2013; Lang, Regester, Lauderdale, Ashbaugh, \& Haring, 2010; Nicoll et al., 2013). However, it remains difficult to establish the effectiveness of each separate component of CBT in the existing literature (Bhaumik, Gangadharan, Hiremath, \& Russell, 2011). Therefore, for individuals with MBID and verbal or cognitive abilities that might constrain effective CBT, add-on approaches to target arousal reduction in a less verbal manner could be considered. For example, body-oriented techniques used in Psychomotor therapy (PMT), including behavioural relaxation techniques (e.g., Progressive Relaxation or "Soles of the Feet", a meditation procedure) to reduce arousal and support anger regulation might be feasible (Kay, Clegg, Emck, \& Standen, 2016; McDonnell et al., 2015; Sturmey, Lindsay, Vause, \& Neil, 2014).

PMT can be used as a complementary treatment for individuals with psychological or behavioural problems, in which a continuum of body-oriented techniques, such as Progressive Relaxation and deep breathing, to movement-oriented techniques, derived from sports and exercises, are allocated (Boerhout, van Busschbach, Wiersma, \& Hoek, 2013; Probst, Knapen, Poot, \& Vancampfort, 2010). These mainly non-verbal exercises are often guided by psychomotor therapists. Although PMT integrates a variety of approaches it emphasises awareness of bodily responses over awareness of emotion (Boerhout et al., 2013; Kay et al., 2016). The aim is to offer a context for participants to increase their interoceptive awareness (i.e., the ability to recognise differences in body signals). Within this therapeutic environment, participants are encouraged to practice with different forms of behaviour to help reduce excessive anger arousal and thereby preclude attempt to using aggression. In this way, CBT techniques and insight are given an extra context in which experiences and training with new forms of behaviour are part of the therapy sessions. Actively evoking here-and-now experiences is a basic principle in PMT (Boerhout et al., 2013; van der Maas et al., 2015; Röhricht, 2009; Zwets et al., 2016). PMT emphasises interoceptive awareness (being aware of changes in body signals) as opposed to placing emphasis awareness of the emotion of anger in an effort to enable individuals with MBID to reflect on the relationship between experiences and feelings (Kay et al., 2016).

Although the effects of PMT or specific body-oriented and movement-oriented interventions on the anger and aggression of individuals with MBID have been investigated in a number of studies, we are not aware of any existing review of that corpus of research. The purpose of this systematic review was to inform practitioners on the efficacy and the evidence-base of PMT by summarising and analysing the participants, intervention procedures, outcomes and certainty of evidence (i.e., research rigour) of PMT studies involving the treatment of anger and aggressive behaviour in people with MBID. Second, we aimed to identify directions for future research that may contribute to ongoing efforts to treat aggression and reduce anger in people with MBID.

\section{Method}

A systematic analysis was conducted of studies that focused on PMT, namely body-oriented or movementoriented interventions, to decrease anger or aggressive behaviour in individuals with MBID. Studies that met predetermined inclusion criteria were analysed and summarised in terms of: (a) participant characteristics; (b) dependent variables; (c) intervention procedures and dosages; (d) intervention outcomes; and (e) certainty of evidence.

\section{Search procedure}

A five-step systematic search procedure was used to identify studies for possible inclusion in this review. First, searches were conducted in five databases: PsychINFO, MEDLINE, CINAHL, ERIC and Web of Science. Search parameters were restricted to only yield peer-reviewed papers written in English that were published between 1980 and 2015. Search terms related to PMT (i.e., "dance and movement therapy", "PMT", "psychomotor physiotherapy", "mindbody intervention", "movement-oriented therapy", "body awareness therapy", "body-oriented therapy", "body psychotherapy") as well terms associated with a broader collection of physiological interventions regularly used by 
psychomotor therapists (i.e., "exercise", "physical activity", "physical training", "sport therapy", "running therapy", "physiotherapy", "yoga", "relaxation", "mindfulness exercise" and "mindfulness-based stress reduction") were paired with terms related to MBID (i.e., "mild intellectual disability", "borderline intellectual disability", "mild learning disability", "mild mental retardation" and "borderline mental retardation") and terms related to anger or aggressive behaviour (i.e., "anger", "aggression" and "aggressive behaviour"). After eliminating duplicates, this combination of search terms across the five electronic databases resulted in 86 potentially eligible studies.

Second, the abstracts (and when necessary, the full texts) of the 86 articles were screened to identify studies that met the inclusion criteria (see inclusion and exclusion criteria). After the application of inclusion criteria, six studies were identified for inclusion. Third, the reference lists of those six studies were reviewed to identify additional studies for possible inclusion, and one additional study was identified for inclusion. Fourth, the surname of the first author of each of the included studies was entered as a search term in the five electronic databases to identify any other potentially eligible studies by the same authors. That process yielded two more studies for inclusion. Finally, in order to identify recent studies that had not yet been entered in databases, hand searches covering January 2015 - November 2015 were completed for the journals that had published two or more of the already included studies. However, no additional studies were identified. Ultimately, a total of nine studies were included as a result of this systematic multi-step search procedure that took place during October 2015 and November 2015.

\section{Inclusion and exclusion criteria}

Studies were included if they met five inclusion criteria. First, the study had to be written in English. Second, the study had to be published between 1980 and November 2015. Third, the study included at least one participant with MBID (IQ 50-85). Fourth, the study had to focus on primarily a body-oriented or movement-oriented intervention (e.g., not a multicomponent anger management treatment package). And fifth, the study had to be an empirical study which evaluated the effectiveness of a movement-oriented or body-oriented intervention. If studies mentioned more than one procedure with different case studies in one paper, only the relevant cases with the PMT interventions were taken into consideration (e.g., Lindsay, Overend, Allan, Williams, \& Black, 1998; Schloss, Smith, Santora, \& Bryant, 1989). Previous reviews (e.g., Ali et al., 2015), theoretical papers (e.g., Young, 2012), intervention studies with a cognitive emphasis (e.g., mindfulness as cognitive intervention), and assessment-only studies (e.g., Willner, Brace, \& Phillips, 2005) were excluded.

\section{Data extraction}

Each included study was coded for: (a) participant characteristics, (b) dependent variables, (c) intervention procedures and dosage, (d) intervention outcomes, and (e) certainty of evidence. Participant characteristics included gender, age, level of intellectual disability, comorbidity and a description of the setting where the participant lives. PMT interventions were described in terms of activities used, intervention session duration and frequency, and whether PMT was given in an individual or group format. The intervention's outcomes effect sizes were calculated as Percentage of Data Points Exceeding the Median (PEM; Ma, 2006); this is the percentage of data from the intervention phase below the median of data during baseline. In some cases, it was possible to calculate the mean PEM for a group of participants within a single-subject study. This was done by first calculating the PEM for each participant individually and then calculating the mean of these percentages. The higher the PEM, the more effective the intervention is in terms of a reduction in aggressive behaviour or anger. If calculating PEM was not possible due to absence of individual information in group designs, the statistical findings as reported by the authors of the studies were summarised. PEM was selected over the percentage of non-overlapping data (PND) because PEM provides an indication of the effect size despite floor and ceiling points and is less sensitive to outliers in baseline compared to PND (Ma, 2006; Parker, Vannest, \& Davis, 2011).

Certainty of evidence (or research rigour) was rated as "inconclusive" or "conclusive" (Millar, Light, \& Schlosser, 2006) as a means to provide an overview of the quality of evidence (Schlosser \& Sigafoos, 2007). This appraisal involved a two-stage process. First, studies lacking an experimental design with a follow-up period were classified as providing inconclusive results and studies with an experimental design (e.g., randomised controlled trial, multiple baseline or reversal design) were identified as having the potential to provide conclusive evidence. Second, experimental studies had to meet four additional standards to be classified as providing conclusive evidence: (a) a convincing demonstration of the intervention effect (PEM $>90 \%$ or a statistically significant decrease of anger or aggressive behaviour in group designs); (b) if relevant, there had to be interobserver agreement above $80 \%$; (c) dependent and independent variables had to be operationally defined; and 
(d) a detailed description of the procedure was given to enable replication of the study.

\section{Reliability of search procedures and interrater agreement}

To ensure the accuracy of the five step systematic search, the first and fourth author independently proceeded through the multi-step search procedure and made an initial determination whether each study met the inclusion or exclusion criteria. Agreement on whether a study should be included or excluded was $90 \%$ (i.e., agreement was obtained on 9 of the 10 studies) with the study of Mullins and Christian (2001) included by one of two reviewers. After discussion between coauthors, the study was excluded because aggressive behaviour was not a target.

After agreement on studies, the first author extracted information to summarise the included studies. The accuracy of these summaries was independently checked by the fifth author, using a checklist that included the summary of the study and five questions regarding summary accuracy. The questions were: (a) Is this an accurate description of the participant(s)?, (b) Is this an accurate description of the focus of the intervention?, (c) Is this an accurate description of the intervention?, (d) Is this an accurate summary of the outcomes?, and (e) is this an accurate description of the certainty of evidence? The fifth author compared the summary with the original study and completed the checklist. If a summary was considered inaccurate, the fifth author edited the summary to improve its accuracy. The resulting summaries were then agreed upon and were used to create Table 1. This procedure was intended to ensure summary accuracy and to provide a measure of interrater agreement on data extraction and analysis. Agreement or disagreement was calculated on 45 items (i.e., five checklist questions $\mathrm{x}$ nine studies). In 37 items (82\%) agreement was obtained at the first independent rating and final agreement after discussion was $100 \%$.

\section{Results}

Table 1 provides an overview of the data extracted from each study.

\section{Participant characteristics}

In total, the nine studies presented data on 120 participants, aged 16-58 years. In eight studies, a total of 39 participants received intervention. In the study of Benson, Rice, and Miranti (1986) a range of participants (10-18) was provided and the exact number receiving intervention was not reported. Most participants were male $(n=84,70 \%)$. Calculating mean age was not possible due to the lack of individual age data in several studies (i.e., Benson et al., 1986; McPhail \& Chamove, 1989; Singh et al., 2013; To \& Chan, 2000). In six studies all of the participants were diagnosed with MBID ( $n=$ 46, 38\%) (i.e., Lindsay et al., 1998; Singh, Wahler, Adkins, Myers, \& Mindfulness Research Group, 2003; Singh et al., 2008, 2011, 2013). In three studies there were also participants with a more severe level of ID included with those with MBID. DSM-IV-TR diagnoses were psychotic disorder NOS $(n=1)$, bipolar disorder without psychotic features $(n=1)$, impulse control disorder NOS and attention deficit hyperactivity disorder - combined type $(n=1)$, paedophilia $(n=1)$, and paraphilia NOS $(n=1)$. Fifty-four participants $(45 \%)$ were recruited from vocation training centres with no information about participant residences, 30 (25\%) were living in a residential facility, 28 (23\%) lived at home or with their parents, and 8 (7\%) resided independently with visits from support staff.

\section{Dependent variables}

Aggressive behaviour was targeted in six studies involving 62 (52\%) participants (i.e., Lindsay et al., 1998; McPhail \& Chamove, 1989; Singh et al., 2003, 2008, 2013; To \& Chan, 2000). Verbal and physical aggression was measured by direct observation of operationally defined target behaviours in six studies, one study used only self-report and two studies combined observation with self-report. Anger was targeted in one study involving 1 (1\%) participant (i.e., Schloss et al., 1989) and anger and aggressive behaviour were both targeted in two studies involving 57 (48\%) participants (i.e., Benson et al., 1986; Singh et al., 2011). Anger was measured twice by observation of anger related body signals, of which one study combined it with self-report. One study only used self-reports. In two studies there were more dependent variables mentioned (total disruptive behaviour, motor disruptive behaviour and other disruptive behaviours, McPhail \& Chamove, 1989; and incidents, selfcontrol, PRN medication, physical restraints, injuries, social integrated activities and physically integrated activities; Singh et al., 2003).

\section{Description of the intervention}

All intervention procedures used in the selected studies involved body-oriented interventions. No movementoriented interventions were described. Progressive muscle relaxation (PMR) or the abbreviated variant, abbreviated progressive relaxation (APR), was utilised 
Table 1. Studies that met predetermined inclusion criteria.

\begin{tabular}{|c|c|c|c|c|c|}
\hline Authors & $\begin{array}{c}\text { Participant } \\
\text { characteristics and } \\
\text { setting }\end{array}$ & $\begin{array}{l}\text { Dependent variables and } \\
\text { design }\end{array}$ & $\begin{array}{l}\text { Intervention } \\
\text { procedures }\end{array}$ & Intervention outcomes & Certainty of evidence \\
\hline $\begin{array}{l}\text { Benson et al. } \\
\text { (1986) }\end{array}$ & $\begin{array}{l}N=54, M=32 \text { y } \\
I Q \text { range }=20-69 \\
\text { Vocational centre }\end{array}$ & $\begin{array}{l}\text { Anger } \\
\text { Aggressive behaviour } \\
\text { Comparing four } \\
\text { interventions } \\
\text { (pre, post, FU) }\end{array}$ & $\begin{array}{l}\text { PMR, group } \\
\text { or self-instruction, } \\
\text { group } \\
\text { or problem-solving, } \\
\text { group } \\
\text { or combined } \\
\text { strategies, group }\end{array}$ & $\begin{array}{l}\text { PMR resulted in significant reduction } \\
\text { in aggressive behaviour, } \\
\text { maintained at FU }\end{array}$ & $\begin{array}{l}\text { Inconclusive: } \\
\text { no control condition }\end{array}$ \\
\hline $\begin{array}{l}\text { Lindsay et al. } \\
\text { (1998) }\end{array}$ & $\begin{array}{l}N=1,58 \text { y } \\
I Q \text { range } 50-69 \\
\text { Living in service for ID }\end{array}$ & $\begin{array}{l}\text { Aggressive behaviour } \\
\text { AB-design with FU }\end{array}$ & APR, individual & $\begin{array}{l}\text { Aggressive incidents dropped, during } \\
\text { FU reduction of incidents was } \\
\text { maintained. PEM }=95 \%\end{array}$ & $\begin{array}{l}\text { Inconclusive: } \\
\text { no experimental } \\
\text { design }\end{array}$ \\
\hline $\begin{array}{l}\text { McPhail and } \\
\text { Chamove } \\
\text { (1989) }\end{array}$ & $\begin{array}{l}N=10, M=34 y \\
I Q \text { range }=20-69 \\
\text { Living at home }\end{array}$ & $\begin{array}{l}\text { Aggressive behaviour } \\
\text { RCT with active control } \\
\text { (plus FU) }\end{array}$ & $\begin{array}{l}\text { APR, group } \\
\text { or story reading, } \\
\text { group }\end{array}$ & $\begin{array}{l}\text { Significant differences in aggressive } \\
\text { behaviour in favour of APR-group. } \\
\text { Aggressive behaviour returned to } \\
\text { baseline during FU }\end{array}$ & $\begin{array}{l}\text { Inconclusive: } \\
\text { low IOA }\end{array}$ \\
\hline $\begin{array}{l}\text { Schloss et al. } \\
\text { (1989) }\end{array}$ & $\begin{array}{l}N=1,26 y \\
I Q \geq 70 \\
\text { Living at home }\end{array}$ & $\begin{array}{l}\text { Anger } \\
\text { Multiple baseline across } \\
\text { situations (including } \\
\text { generalisation, FU) }\end{array}$ & $\begin{array}{l}\text { PMR and systematic } \\
\text { desensitisation, } \\
\text { individual }\end{array}$ & $\begin{array}{l}\text { Reductions in anger responses. } \\
\text { Maintained during generalisation } \\
\text { and FU. Mean PEM }=98 \%\end{array}$ & Conclusive \\
\hline $\begin{array}{l}\text { Singh et al. } \\
(2003)\end{array}$ & $\begin{array}{l}N=1,27 \text { y } \\
I Q \text { range = } 50-69 \\
\text { Living at an } \\
\text { institution }\end{array}$ & $\begin{array}{l}\text { Aggressive behaviour } \\
\text { AB-design with FU }\end{array}$ & $\begin{array}{l}\text { Soles of the feet, } \\
\text { individual }\end{array}$ & $\begin{array}{l}\text { Reductions in aggressive behaviour, } \\
\text { maintained during FU. PEM }=100 \%\end{array}$ & $\begin{array}{l}\text { Inconclusive: } \\
\text { no experimental } \\
\text { design }\end{array}$ \\
\hline $\begin{array}{l}\text { Singh et al. } \\
(2008)\end{array}$ & $\begin{array}{l}N=6, M=29 y \\
1 \mathrm{IQ} \text { range }=50-69, \\
5 \mathrm{IQ} \geq 70 \\
\text { Forensic setting for } \\
\text { individuals with ID }\end{array}$ & $\begin{array}{l}\text { Aggressive behaviour } \\
\text { Multiple baseline design } \\
\text { (plus FU) }\end{array}$ & $\begin{array}{l}\text { Soles of the feet, } \\
\text { individual }\end{array}$ & $\begin{array}{l}\text { Reductions in aggressive behaviour } \\
\text { Mean PEM }=96 \%\end{array}$ & Conclusive \\
\hline $\begin{array}{l}\text { Singh et al. } \\
(2011)\end{array}$ & $\begin{array}{l}N=3, M=30 y \\
I Q \text { range }=50-69 \\
\text { Living at home (2) or } \\
\text { supported living (1) }\end{array}$ & $\begin{array}{l}\text { Anger and } \\
\text { Aggressive behaviour } \\
\text { Multiple baseline design } \\
\text { (plus FU) }\end{array}$ & $\begin{array}{l}\text { Soles of the feet, } \\
\text { individual }\end{array}$ & $\begin{array}{l}\text { Anger and aggressive behaviour } \\
\text { reduced during intervention and } \\
\text { effect was maintained during FU. } \\
\text { Mean PEM anger }=88 \% \text {. } \\
\text { Mean PEM aggressive behaviour = } \\
55 \%\end{array}$ & $\begin{array}{l}\text { Inconclusive: } \\
\text { unconvincing effect }\end{array}$ \\
\hline $\begin{array}{l}\text { Singh et al. } \\
\text { (2013) }\end{array}$ & $\begin{array}{l}N=17 / 17^{\mathrm{a}} \\
M=23 / 23 \text { y } \\
\text { IQ range }=50-69 \\
\text { Living with parents } \\
\quad(8 / 5), \text { supported } \\
\text { living }(9 / 12)\end{array}$ & $\begin{array}{l}\text { Aggressive behaviour } \\
\text { RCT with waiting list } \\
\text { control (plus FU) }\end{array}$ & $\begin{array}{l}\text { Soles of the Feet, } \\
\text { individual } \\
\text { or waiting list, } \\
\text { individual }\end{array}$ & $\begin{array}{l}\text { Significant reduction in aggressive } \\
\text { behaviour compared to control. } \\
\text { Effect maintained during FU }\end{array}$ & Conclusive \\
\hline $\begin{array}{l}\text { To and Chan } \\
(2000)\end{array}$ & $\begin{array}{l}N=10 \text {, age range: } \\
16-46 \mathrm{y} \\
\text { IQ range }=40-70 \\
\text { Inpatient setting }\end{array}$ & $\begin{array}{l}\text { Aggressive behaviour } \\
\text { Pretest and posttest- } \\
\text { design }\end{array}$ & APR, group & $\begin{array}{l}\text { No significant reduction of aggressive } \\
\text { behaviour }\end{array}$ & $\begin{array}{l}\text { Inconclusive: } \\
\text { no experimental } \\
\text { design, } \\
\text { unconvincing effect }\end{array}$ \\
\hline
\end{tabular}

in five studies $(n=76,63 \%)$ (i.e., Benson et al., 1986; Lindsay et al., 1998; McPhail \& Chamove, 1989; Schloss et al., 1989; To \& Chan, 2000). One of these studies combined PMR and systematic desensitisation (Schloss et al., 1989). Benson et al. (1986) compared four procedures: APR, self-instruction, problem-solving and anger management (including relaxation, self-instruction and problem-solving). One study described three individuals who were given different interventions, but only one case involved PMT and the other two cases were excluded from analysis (Lindsay et al., 1998). In the studies in which PMR or APR was used, the focus was on contracting and relaxing specific muscle groups, aimed at arousal reduction. The other four studies used the meditation procedure "Soles of the Feet" as intervention ( $n=44,37 \%$ ) (i.e., Singh et al., 2003, 2008, $2011,2013)$. The participants receiving "Soles of the Feet" were asked to think of a situation where anger was experienced after which they were asked to bring their attention to the soles of their feet, while holding on to the feeling of anger. The therapist mentioned anger related body signals (e.g., accelerated breathing). The participant's attention is shifted as they move their toes and concentrate on feeling the texture of the socks or the pressure of the shoes on the heel. The intent of this calming relaxation exercise is to predicate arousal reduction.

Intervention dosage varied a great deal across studies. Individual sessions ranged in duration from 15 to 90 minutes. Session frequency ranged from twice daily to 
once per week and the overall period of time from intervention onset to completion of data collection ranged between 5 days and 27 months. Some studies did not report complete information of intervention dosage (i.e., Lindsay et al., 1998; Schloss et al., 1989; Singh et al., 2008, 2011).

Three studies provided the original or the abbreviated PR-treatment in small groups, ranging from three to nine participants (i.e., Benson et al., 1986; McPhail \& Chamove, 1989; To \& Chan, 2000). The remainder of studies provided intervention in an individual format involving only one client and therapist at a time.

\section{Intervention outcomes}

In total, seven out of nine studies reported a substantial reduction in aggressive behaviour or anger. Six of eight studies focusing on aggressive behaviour reported a substantial reduction with PEM higher than $90 \%$ in three studies (Lindsay et al., 1998; Singh et al., 2003, 2008) and two studies demonstrated significant differences between the intervention group and control group (McPhail \& Chamove, 1989; Singh et al., 2013). One study did not yield significant differences between treatment and control group solely focused on aggressive behaviour (To \& Chan, 2000). The study by Benson et al. (1986) found a significant effect of PMR and other interventions on aggressive behaviour. Singh et al. (2011) failed at demonstrating a substantial reduction on both anger and aggressive behaviour in their study as PEM on anger was $88 \%$ and PEM on aggressive behaviour was $55 \%$. One study focused solely on anger: Schloss et al. (1989) found a convincing reduction on anger (PEM $>90 \%$ ).

Eight studies collected follow-up data and six of those studies included only individuals with MBID (Lindsay et al., 1998; Schloss et al., 1989; Singh et al., 2003, 2008, 2011, 2013). For the 29 participants with follow-up data, all studies with FU period except for two, the reduction of aggressive behaviour or anger was reported as maintained from three to 24 months. In the study of Singh et al. (2011), the initial positive effect on anger was not maintained at 24 months' follow-up. Benson et al. (1986) and McPhail and Chamove (1989) included participants with varying levels of ID. The initial reduction in aggressive behaviour was maintained at four to five week follow-up in the study by Benson et al. (1986) but was not maintained at 12 week follow-up in the study by McPhail and Chamove (1989). Follow-up data specific to participants with MBID in those studies could not be disaggregated.

\section{Certainty of evidence}

Most studies used single-subject research designs but that group included studies utilising AB-designs not capable of demonstrating experimental control (Lindsay et al., 1998; Singh et al., 2003). Three studies using multiple baseline designs met the experimental design criterion (Schloss et al., 1989; Singh et al., 2008, 2011). There were also four group designs included. One study had a non-experimental group design, namely a pretest posttest-design (To \& Chan, 2000) and the study by Benson et al. (1986) compared four active interventions without a control condition. Two studies were Randomised Clinical Trials (RCT), one with an active control group (McPhail \& Chamove, 1989) and one with a waiting list control group (Singh et al., 2013). The certainty of evidence was rated as conclusive for two out of eight reviewed studies on aggressive behaviour (i.e., Singh et al., 2008, 2013) and one out of three reviewed studies on anger (Schloss et al., 1989). Four studies were rated as inconclusive because of a lack of experimental control (Benson et al., 1986; Lindsay et al., 1998; Singh et al., 2003; To \& Chan, 2000), although three of these studies suggested an effect of PMT on aggressive behaviour (Benson et al., 1986; Lindsay et al., 1998; Singh et al., 2003). One study was rated inconclusive due to low interrater agreement (McPhail \& Chamove, 1989). One study was rated as inconclusive due to non-significant results on aggressive behaviour or anger (Singh et al., 2011).

\section{Discussion}

This systematic review evaluated the effectiveness of body-oriented PMT interventions (no movementoriented studies met inclusion criteria) for reducing anger and aggressive behaviour in individuals with MBID. The PMT body-oriented intervention components, as used in the studies that met the inclusion criteria, include PMR and the meditation procedure "Soles of the Feet". Most studies reported an intervention effect on anger or aggressive behaviour, but these results need to be interpreted with caution due to overall lack of research rigour. For all but three studies certainty of evidence was rated as inconclusive, mostly due to a lack of experimental control. Based on the criteria for identification of empirically supported therapies of Nathan and Gorman (1998), Roth and Fonagy (1996) and Spirito (1999) (as cited in Chambless \& Ollendick, 2001) we can conclude that PMT is a promising treatment for anger and aggressive behaviour in individuals with MBID. However, the research-base in this area does not yet meet commonly accepted definitions of evidence-based 
practice (e.g., Sturmey \& Didden, 2014). Future research involving studies with a stronger methodological character aimed at identifying PMT's mechanisms of action (e.g., improved interoceptive awareness) appears warranted.

The absence of movement-oriented intervention components in the corpus of research is surprising given that fitness and exercise-based interventions have been demonstrated to be effective in the treatment of aggressive behaviour in individuals with more severe ID (Ogg-Groenendaal, Hermans, \& Claessens, 2014) and individuals with pervasive developmental disabilities (Lang, Koegel, et al., 2010). Future research involving movement-oriented PMT intervention components either in isolation or in combination with body-oriented components may be fruitful.

The mechanism of action posited to underlie bodyoriented PMT depends on the reduction of anger or on preventing the emergence of an angry emotional state and on the augmentation of coping skills in order to reduce anger emergence. The assumed mechanisms of action of PMT targeting anger and aggressive behaviour in individuals with MBID therefore involve anger related IA and coping skills. This is in line with the assumption that anger has to be experienced (by anger related IA) and that efficient coping skills should be used in case the participant experiences anger (Gratz \& Roemer, 2004; Mehling et al., 2012). As for the first assumed working mechanism, it is not clear whether PMT, using body-oriented interventions, should focus specifically on anger-related IA, IA in general or on some other mechanism not yet recognised in the PMT research-base. The included studies on PMR emphasise only on IA in general (e.g., feeling the difference between tension and relaxation in your muscle). In the meditation procedure the focus is on general IA, especially tactile information, as well as on anger-related IA (e.g., what do you feel in your body when you are angry); however, this is not accentuated during the exercises. As individuals with MBID often have problems with generalisation and transfer to daily life, one could assume that it is helpful to focus on anger-related IA to prevent becoming aggressive. This could help them to focus on relevant information to recognise their emotion. Focusing on relevant information, which is often a problem in individuals with MBID, facilitates transfer and generalisation (Alberto \& Troutmen, 2003). Second, coping skills are assumed to be part of the mechanism of action responsible for improvements and were taught in all of the included studies. In PMR the focus is on relaxation as a coping skill to reduce arousal and in the meditation procedure attention on tactile perception is taught as a coping skill. In this case, IA is used to focus the attention on a neutral point of the body as to down regulate arousal. Future research on the mechanisms of action of PMT is warranted.

In this review three studies stated that anger was focused on during intervention. Only one study was considered as providing conclusive evidence (Schloss et al., 1989), in one study the reduction of anger resulted in a PEM of $88 \%$, falling slightly short of the $90 \%$ or better PEM criteria (Singh et al., 2011). Therefore, the mechanism of action thought responsible for the beneficial effects of this class of interventions cannot be confirmed with this population and a number of alternative explanations for the benefits of PMT remain possible. Further, the extent to which these procedures actually result in a beneficial reduction of anger has not been sufficiently demonstrated. Future research towards identifying more direct and accurate ways to assess anger in people with MBID and then towards elucidation of the mechanism of action for PMT is needed. In the included studies anger was measured by focusing on anger body signals by observation of movements and facial expression (Benson et al., 1986; Schloss et al., 1989) and self-reports (Benson et al., 1986; Singh et al., 2011). In terms of more accurate measurement, physiological correlates of anger, such as increased heart rate or respiration and possibly cortisol levels are worthy of further research consideration. In the existing research, only one study provides information on the awareness of anger-related body signals (e.g., furrowed brows or increased heart rate) in order to recognise anger (Singh et al., 2011). A more thorough understanding of the variables that underlie effective intervention approaches achieved through more accurate measurement of the key constructs could lead to the modification of the intervention (or creation of a novel approach) that is more efficient or effective.

Because certainty of evidence of the majority of studies is rated as inconclusive mostly due to absence of experimental control, this review does not yet support the use of these procedures in contexts where researchbased or evidence-based practices are mandated. However, in cases where existing evidence-based practices (e.g., function-based operant interventions) have failed to yield desired outcomes or when research indicates that an individual's characteristics are not well suited for a treatment approach tailored for a different population (e.g., when CBT is precluded by an individual's verbal or cognitive deficits), PMT may be considered a potential treatment option (McDonnell et al., 2015; Reynolds \& Field, 2013). Because PMT is primarily a nonverbal approach for teaching skills that can be used across environments and social situations it may be best used as a complementary therapy to augment 
other approaches such as CBT and function-based behavioural intervention (Probst et al., 2010). PMT is consistent with previous research suggesting that efforts to reduce aggression in individuals with MBID should aim to teach people self-management skills, functional skills, emotional regulation skills and problem-solving skills (Didden et al., 2016). Future research could aim to evaluate the effect of PMT in individuals with MBID as complementary therapy compared to treatment as usual, similar to the study on aggression regulation in patients with eating disorder (Boerhout, Swart, van Busschbach, \& Hoek, 2016) and the study in chronic pain revalidation in individuals without MBID (van der Maas et al., 2015).

This systematic review has several limitations. To minimise bias, multiple databases were searched and hand searches were conducted. Although this search was systematic and involved predefined inclusion criteria, the possibility of publication bias remains.

It has been noted in previous research that studies reporting significant positive results are more likely to be published (Sutton, 2009). Therefore, reviews aimed at identifying evidence-based practices that include only peer-reviewed published studies may also be affected by this publication bias. An effective systematic review or meta-analysis should stimulate replication and extension studies on those interventions (see, e.g., Francis, 2012). Therefore, when a limited number of studies are identified for inclusion in a review, it is unclear whether this is because few researchers have investigated the topic or if there has been substantial research but that the findings of those studies were inconclusive or nonsignificant. This review identified a larger number of studies focused on body-oriented interventions (particularly progressive relaxation and "Soles of the Feet") and a lack of articles on movement-oriented interventions. Therefore, it is not possible to determine if (a) movement oriented interventions are rarely used in clinical practice; (b) these interventions are used clinically but no effort is made to study results; or (c) research has been conducted but was not published due to ambiguous or negative results. We conclude that the lack of data on other body- and movement-oriented interventions does not necessarily mean those interventions are ineffective or unworthy of future research.

Two different ways of reporting the effectiveness of the interventions were applied (i.e., significant differences in group studies and PEM in case-studies) and a direct comparison of these results across studies is not possible in light of these differences. However, given that the results from both single-case design and group design studies were similarly mixed and the conclusion reached by the review was conservative (i.e., PMT was not identified as an evidence-based practice), the limitation is minor.

In this review both individuals with mild intellectual disability (IQ 50-69) and borderline intellectual functioning (IQ 70-85) are included. This is in accordance with how treatment is organised in the Netherlands and Belgium. So this review did not itemise these two groups as would the case in, for example, the UK and US. It should be noted that in the present review most participants had a mild intellectual disability (see Table 1).

Despite these limitations, the results of this review provide a note of caution to practitioners interested in PMT and suggests its use be limited to cases that fail to respond to evidence-based interventions or as a supplement to evidence-based intervention packages. Additionally, the findings of this review suggest progressive relaxation and "Soles of the Feet" meditation may have a positive effect but the potential benefit of other body-oriented and movement interventions remains unclear. Future research towards providing a stronger demonstration of benefit (i.e., increased certainty of evidence); better understanding of mechanisms of action; improved measurement approaches for target variables (e.g., anger) and expanding PMT components to include body-movement strategies utilised with other populations appears necessary.

\section{Discourse statement}

No potential conflict of interest was reported by the authors.

\section{Funding}

This work was supported by the Nederlandse Organisatie voor Wetenschappelijk Onderzoek (NWO) [grant number 023.004. 138] and Oldenkamp [grant 2013]. Stichting Oldenkamp is a small Dutch foundation that aims to financially support research on non-verbal therapeutic interventions, especially in forensic psychiatry.

\section{ORCID}

Tina Bellemans (D) http://orcid.org/0000-0002-9181-5840

\section{References}

Alberto, P. A., \& Troutman, A. C. (2003). Applied behavior analysis for teachers. Upper Saddle River, NJ: Merril/ Prentice Hall.

Ali, A., Hall, I., Blickwedel, J., \& Hassiotis, A. (2015). Behavioural and cognitive-behavioural interventions for outwardly-directed aggressive behaviour in people with intellectual disabilities. Cochrane Database of Systematic Reviews, 4, CD003406. doi:10.1002/14651858.CD003406. pub4 
Benson, B. A., Rice, C. J., \& Miranti, V. S. (1986). Effects of anger management training with mentally retarded adults in group treatment. Journal of Consulting and Clinical Psychology, 54(5), 728-729.

Bhaumik, S., Gangadharan, S., Hiremath, A., \& Russell, P. S. S. (2011). Psychological treatments in intellectual disability: The challenges of building a good evidence base. The British Journal of Psychiatry, 198(6), 428-430.

Boerhout, C., Swart, M., van Busschbach, J. T., \& Hoek, H. W. (2016). Effect of aggression regulation on eating disorder pathology: RCT of a brief body and movement oriented intervention. European Eating Disorders Review, 24, 114-121.

Boerhout, C., van Busschbach, J. T., Wiersma, D., \& Hoek, H. W. (2013). Psychomotor therapy and aggression regulation in eating disorders. Body, Movement and Dance in Psychotherapy: An International Journal for Theory, Research and Practice, 8(4), 241-253.

Brosnan, J., \& Healy, O. (2011). A review of behavioral interventions for the treatment of aggression in individuals with developmental disabilities. Research in Developmental Disabilities, 32, 437-446.

Chambless, D. L., \& Ollendick, T. H. (2001). Empirically supported psychological interventions: Controversies and evidence. Annual Review of Psychology, 52(1), 685-716.

Crotty, G., Doody, O., \& Lyons, R. (2014). Identifying the prevalence of aggressive behaviour reported by registered intellectual disability nurses in residential intellectual disability services: An Irish perspective. Advances in Mental Health and Intellectual Disabilities, 8, 174-187.

Davies, L., \& Oliver, C. (2013). The age related prevalence of aggression and self-injury in persons with an intellectual disability: A review. Research in Developmental Disabilities, 34, 764-775.

Didden, R., Lindsay, W. R., Lang, R., Sigafoos, J., Deb, S., Wiersma, J., ... Lancioni, G. E. (2016). Aggressive behavior. In N. N. Singh (Ed.), Clinical handbook of evidence-based practices for individuals with intellectual disabilities (pp. 727-750). New York, NY: Springer.

Francis, G. (2012). The psychology of replication and replication in psychology. Perspectives on Psychological Science, 7 , 585-594.

Gratz, K. L., \& Roemer, L. (2004). Multidimensional assessment of emotion regulation and dysregulation: Development, factor structure, and initial validation of the difficulties in emotion regulation scale. Journal of Psychopathology and Behavioral Assessment, 26(1), 41-54.

Hamelin, J., Travis, R., \& Sturmey, P. (2013). Anger management and intellectual disabilities: A systematic review. Journal of Mental Health Research in Intellectual Disabilities, 6(1), 60-70.

Hensel, J. M., Lunsky, Y., \& Dewa, C. S. (2014). The mediating effect of severity of client aggression on burnout between hospital inpatient and community residential staff who support adults with intellectual disabilities. Journal of Clinical Nursing, 23(9-10), 1332-1341.

Kay, J. J., Clegg, J. A., Emck, C., \& Standen, P. J. (2016). The feasibility of psychomotor therapy in acute mental health services for adults with intellectual disability. Journal of Intellectual and Developmental Disability, 41(1), 54-60.

Lang, R., Koegel, L., Ashbaugh, K., Regester, A., Ence, W., \& Smith, W. (2010). Physical exercise and individuals with autism spectrum disorders: A systematic review. Research in Autism Spectrum Disorders, 4, 565-576.

Lang, R., Regester, A., Lauderdale, S., Ashbaugh, K., \& Haring, A. (2010). Treatment of anxiety in autism spectrum disorders using cognitive behavior therapy: A systematic review. Developmental Neurorehabilitation, 13, 53-63.

Larkin, P., Jahoda, A., \& MacMahon, K. (2013). The social information processing model as a framework for explaining frequent aggression in adults with mild to moderate intellectual disabilities: A systematic review of the evidence. Journal of Applied Research in Intellectual Disabilities, 26, 447-465.

Lindsay, W. R., Overend, H., Allan, R., Williams, C., \& Black, L. (1998). Using specific approaches for individual problems in the management of anger and aggression. British Journal of Learning Disabilities, 26(2), 44-50.

Lundqvist, L. O. (2013). Prevalence and risk markers of behavior problems among adults with intellectual disabilities: A total population study in Orebro county, Sweden. Research in Developmental Disabilities, 34(4), 1346-1356.

Ma, H. (2006). An alternative method for quantitative synthesis of single-subject researchers: Percentage of data points exceeding the median. Behavior Modification, 30 (5), 598-617.

van der Maas, L. C. C., Köke, A., Pont, M., Bosscher, R. J., Twisk, J. W. R., Janssen, T. W. J., \& Peters, M. L. (2015). Improving the multidisciplinary treatment of chronic pain by stimulating body awareness: A cluster-randomized trial. The Clinical Journal of Pain, 31(7), 660-669.

McDonnell, A., McCreadie, M., Mills, R., Deveau, R., Anker, R., \& Hayden, J. (2015). The role of physiological arousal in the management of challenging behaviours in individuals with autistic spectrum disorders. Research in Developmental Disabilities, 36, 311-322.

McPhail, C. H., \& Chamove, A. S. (1989). Relaxation reduces disruption in mentally handicapped adults. Journal of Intellectual Disability Research, 33(5), 399-406.

Mehling, W. E., Price, C., Daubenmier, J. J., Acree, M., Bartmess, E., \& Stewart, A. (2012). The multidimensional assessment of interoceptive awareness (MAIA). PLoS One, 7(11), e48230. doi:10.1371/journal.pone.0048230

Millar, D. C., Light, J. C., \& Schlosser, R. W. (2006). The impact of augmentative and alternative communication intervention on the speech production of individuals with developmental disabilities: A research review. Journal of Speech Language and Hearing Research, 49(2), 248-264.

Mullins, J. L., \& Christian, L. (2001). The effects of progressive relaxation training on the disruptive behavior of a boy with autism. Research in Developmental Disabilities, 22(6), 449462.

Nathan, P. E., \& Gorman, J. M. (1998). Treatments that work. New York, NY: Oxford University Press.

Nicoll, M., Beail, N., \& Saxon, D. (2013). Cognitive behavioural treatment for anger in adults with intellectual disabilities: A systematic review and meta-analysis. Journal of Applied Research in Intellectual Disabilities, 26(1), 47-62.

Novaco, R. W. (1994). Anger as a risk factor for violence among the mentally disordered. In J. Monahan \& H. J. Streadman (Eds.), Violence and disorder: Developments in risk assessment (pp. 21-59). Chicago, IL: University of Chicago Press. 
Ogg-Groenendaal, M., Hermans, H., \& Claessens, B. (2014). A systematic review on the effect of exercise interventions on challenging behavior for people with intellectual disabilities. Research in Developmental Disabilities, 35(7), 1507-1517.

Parker, R. I., Vannest, K. J., \& Davis, J. L. (2011). Effect size in single-case research: A review of nine nonoverlap techniques. Behavior Modification, 35(4), 303-322.

Probst, M., Knapen, J., Poot, G., \& Vancampfort, D. (2010). Psychomotor therapy and psychiatry: What's in a name? The Open Complementary Medicine Journal, 2, 105-113.

Reynolds, P., \& Field, L. (2013). Audit of group-based activities in an inpatient assessment and treatment unit for individuals with learning disabilities. British Journal of Learning Disabilities, 41(4), 273-279.

Röhricht, F. (2009). Body oriented psychotherapy. The state of the art in empirical research and evidence-based practice: A clinical perspective. Body, Movement and Dance in Psychotherapy, 4, 135-156.

Roth, A., \& Fonagy, P. (1996). What works for whom?” A critical review of psychotherapy research. New York, NY: The Guilford Press.

Schloss, P. J., Smith, M., Santora, C., \& Bryant, R. (1989). A respondent conditioning approach to reducing anger responses of a dually diagnosed man with mild mental retardation. Behavior Therapy, 20, 459-464.

Schlosser, R., \& Sigafoos, J. (2007). Moving evidence-based practice forward. Evidence-based Communication Assessment and Intervention, 1(1), 1-3.

Singh, N. N., Lancioni, G. E., Karazsia, B. T., Winton, A. S., Myers, R. E., Singh, A. N., ... Singh, J. (2013). Mindfulness-based treatment of aggression in individuals with mild intellectual disabilities: A waiting list control study. Mindfulness, 4(2), 158-167.

Singh, N. N., Lancioni, G. E., Winton, A. S., Singh, A. N., Adkins, A. D., \& Singh, J. (2008). Clinical and benefitcost outcomes of teaching a mindfulness-based procedure to adult offenders with intellectual disabilities. Behavior Modification, 32(5), 622-637.

Singh, N. N., Lancioni, G. E., Winton, A. S., Singh, J., Singh, A. N., \& Singh, A. D. (2011). Peer with intellectual disabilities as a mindfulness-based anger and aggression management therapist. Research in Developmental Disabilities, 32(6), $2690-2696$.
Singh, N. N., Wahler, R. G., Adkins, A. D., Myers, R. E., \& Mindfulness Research Group. (2003). Soles of the feet: A mindfulness-based self-control intervention for aggression by an individual with mild mental retardation and mental illness. Research in Developmental Disabilities, 24(3), 158-169.

Spirito, A. (1999). Introduction to special series on empirically supported treatments in pediatric psychology. Journal of Pediatric Psychology, 24(2), 87-90.

Sturmey, P., \& Didden, R. (Eds.). (2014). Evidence-based practice and intellectual disabilities. London: Wiley Blackwell.

Sturmey, P., Lindsay, W., Vause, T., \& Neil, N. (2014). Anxiety disorders. In P. Sturmey \& R. Didden (Eds.), Evidence-based practice and intellectual disabilities (pp. 235-260). London: Wiley Blackwell.

Sutton, A. J. (2009). Publication bias. In H. Cooper, L. Hedges, \& J. Valentine (Eds.), The handbook of research synthesis and meta-analysis (pp. 435-452). New York, NY: Russell Sage Foundation.

Taylor, J. L., \& Novaco, R. W. (2005). Anger treatment for people with developmental disabilities: A theory, evidence and manual-based approach. Chichester: Wiley.

To, M. Y. F., \& Chan, S. (2000). Evaluating the effectiveness of progressive muscle relaxation in reducing the aggressive behaviors of mentally handicapped patients. Archives of Psychiatric Nursing, 14(1), 39-46.

Vereenooghe, L., \& Langdon, P. E. (2013). Psychological therapies for people with intellectual disabilities: A systematic review and meta-analysis. Research in Developmental Disabilities, 34, 4085-4102.

Willner, P., Brace, N., \& Phillips, J. (2005). Assessment of anger coping skills in individuals with intellectual disabilities. Journal of Intellectual Disability Research, 49(5), 329-339.

Woods, P., \& Ashley, C. (2007). Violence and aggression: A literature review. Journal of Psychiatric And Mental Health Nursing, 14(7), 652-660.

Young, S. (2012). Recommendations for teaching physical education to students with EBDs. Strategies: A Journal for Physical and Sport Educator, 25(6), 8-11.

Zwets, A. J., Hornsveld, R. H., Muris, P., Kanters, T., Langstraat, E., \& van Marle, H. J. (2016). Psychomotor therapy as an additive intervention for violent forensic psychiatric inpatients: A pilot study. International Journal of Forensic Mental Health, 15(3), 222-234. 